\title{
Long-term outcomes of tracheal stents removal under fluoroscopy guidance: comparison of tracheal fistulas and tracheal stenosis
}

Yonghua $\mathrm{Bi}^{1+}$, Jindong $\mathrm{Li}^{2+}$, Liangliang Bai ${ }^{1}$, Xinwei $\operatorname{Han}^{1 *}$ (D) and Jianzhuang Ren ${ }^{1 *}$

\begin{abstract}
Background: Endoscopic removal is the most common method for removal of tracheal stents. Few studies have reported the technique of fluoroscopy-guided stent removal for tracheal fistula and tracheal stenosis. We aimed to study the safety and efficacy of fluoroscopy-guided stent removal as well as the optimal duration for stent usage.

Methods: We conducted a retrospective analysis of 152 patients who underwent fluoroscopy-guided stent removal from January 2011 to June 2017. Reasons for stent implantation were tracheal fistula in 85 patients (TF group), and tracheal stenosis in 67 patients (TS group). All patients underwent tracheal CT scans before stent removal and during follow up. The technical success rate, complications, and survival rate were compared between the two groups.

Results: The technical success rate of stent removal was 98.9 and $97.4 \%$, respectively for the TF and TS group. Removal was routine for half of patients, and in the remainder, excessive granulation tissue was the common indications for stent removal, which was found after stenting at $142.1 \pm 25.9$ days in the TF group, and at $89.9 \pm$ 15.0 day in the TS group. The total incidence of complications was 21.1 and $22.4 \%$, respectively, for the TF and TS groups. Perioperative death occurred in one patient in the TF group, and two patients in the TS group. Recurrence of fistula or stenosis requiring re-stenting was the most comment complication in both groups. The 0.5-, 3-, 6-year survival rates were 90.3, 59.6, and 36.1\% for TF group, and 80.4, 75.7, 75.7\% for TS group.

Conclusions: Fluoroscopic removal of tracheal stents is safe and effective for both tracheal fistula and tracheal stenosis, with no significant difference in outcomes. Clinicians should pay attention to the risk of hemoptysis for patients with malignant tumors and a combination with endoscopic hemostasis may help improve its safety.
\end{abstract}

Keywords: Respiratory tract fistula, Tracheal stenosis, Stents removal, Fluoroscopy, Postoperative complications

\footnotetext{
*Correspondence: dreamweaver08@126.com; rrjjzzjrk@126.com

${ }^{\dagger}$ Yonghua Bi and Jindong Li contributed equally to this work and share cofirst authors.

'Department of Interventional Radiology, The First Affiliated Hospital of Zhengzhou University, No.1, East Jian She Road, Zhengzhou 450052, China Full list of author information is available at the end of the article
}

(C) The Author(s). 2021 Open Access This article is licensed under a Creative Commons Attribution 4.0 International License, which permits use, sharing, adaptation, distribution and reproduction in any medium or format, as long as you give appropriate credit to the original author(s) and the source, provide a link to the Creative Commons licence, and indicate if changes were made. The images or other third party material in this article are included in the article's Creative Commons. licence, unless indicated otherwise in a credit line to the material. If material is not included in the article's Creative Commons licence and your intended use is not permitted by statutory regulation or exceeds the permitted use, you will need to obtain permission directly from the copyright holder. To view a copy of this licence, visit http://creativecommons.org/licenses/by/4.0/ The Creative Commons Public Domain Dedication waiver (http://creativecommons.org/publicdomain/zero/1.0/) applies to the data made available in this article, unless otherwise stated in a credit line to the data. 


\section{Background}

Tracheal fistula and/or tracheal stenosis are severe complications after open thoracic surgery, endotracheal intubation injury, endobronchial tuberculosis, and thoracic trauma [1]. These complications often show high rates of mortality and disability rates. Unfortunately, traditional conservative treatment shows a poor curative effect. Although tracheal resection with primary anastomosis is the standard of care for the treatment of tracheal stenosis, tracheal resection is not suitable for long segmental stenosis. Additionally, some patients may not be willing to undergo open surgery because they are too weak or have significant comorbidities [2]. Since selfexpanding metal stents were first used to treat bronchial obstruction in 1989 [3], the efficacy and safety of tracheal stents has been proven for the treatment of tracheal fistula [4-7] or tracheal stenosis [8-13]. However, tracheal stent placement may be accompanied by a series of complications, such as restenosis, migration, fracture, or mucous plugging [14], which make stent removal necessary. Endoscopic removal is the most common method reported for removal of tracheal stents [15-20]. Few studies have reported the technique of tracheal stent removal under fluoroscopic guidance [12, 21, 22]. Is fluoroscopic removal of tracheal stents safe and effective? How long after implantation should the tracheal stent be removed? Topics of ongoing investigation include the safety and efficacy of fluoroscopy-guided stent removal as well as the optimal duration for stent usage. We compared the outcomes and complications associated with fluoroscopy-guided removal of tracheal stents implanted for tracheal fistula and tracheal stenosis.

\section{Methods}

\section{Patients}

This retrospective study was approved by the Ethics Committee and Medical Records Management Section of our University, and informed consent was waived. We retrospectively reviewed the records of a total of $152 \mathrm{pa}$ tients who underwent fluoroscopy-guided stent removal from January 2011 to June 2017 in our department. Of these, 85 patients underwent removal of stents
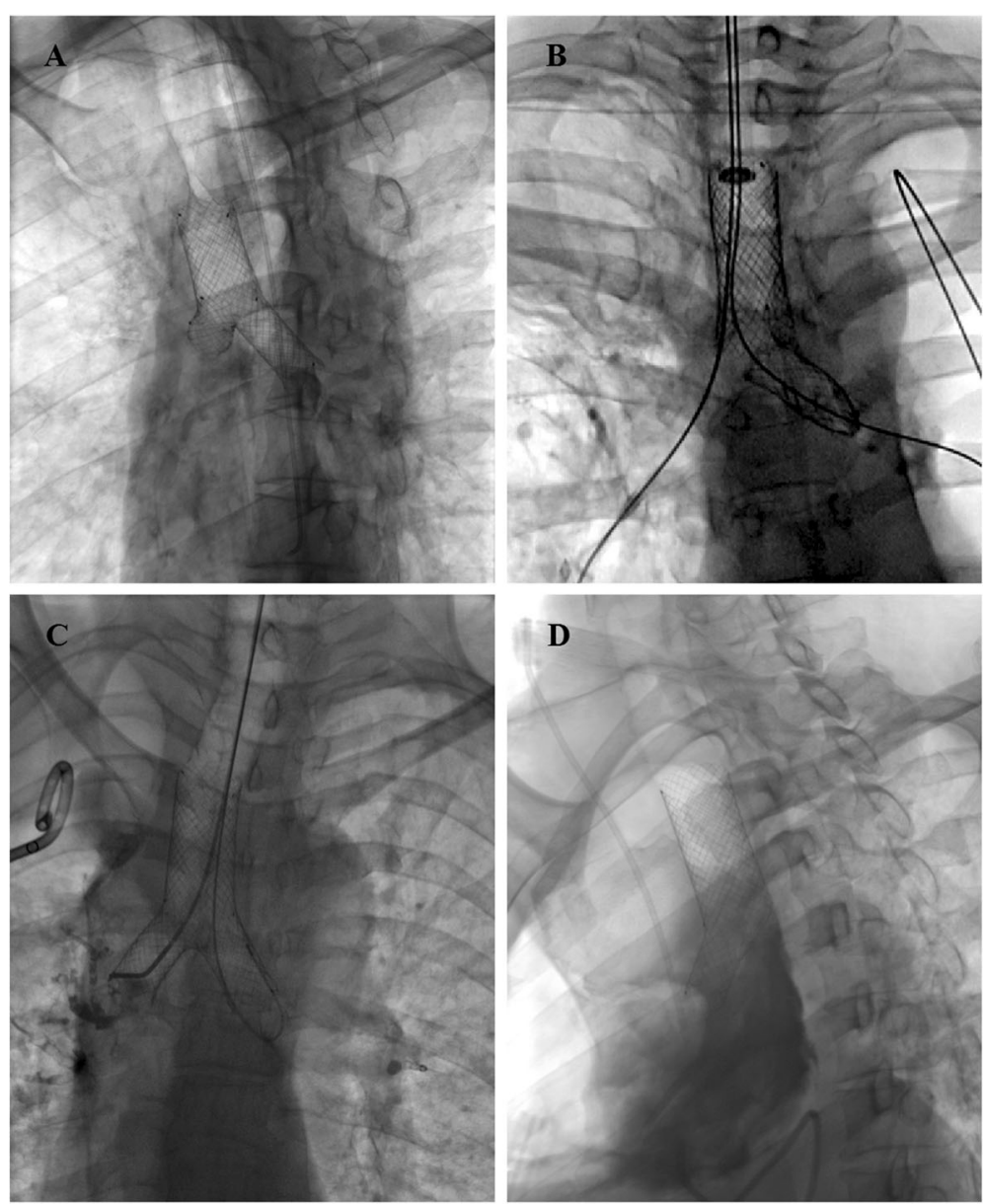

Fig. 1 Types of individualized tracheal stents under fluoroscope. a Y-shaped single-plugged tracheal stent, b plugged bullet-shaped tracheal stent, c Y-type tracheal stent, $\mathbf{d}$ L-type tracheal stent 
implanted for tracheal fistula (TF group), and 67 patients underwent removal of stents implanted for tracheal stenosis (TS group). More than $50 \%$ of patients underwent routine removal in both groups to avoid long-term complications even if they show no obvious symptoms or signs.

\section{Tracheal stent}

Tracheal stents were designed and manufactured according to individual tracheal shape and size measured by CT examination (Nanjing Micro-Tech Medical Company, Nanjing, China), and woven with a temperaturememory nickel-titanium alloy wire. All tracheal stents for fistula were fully covered in TF group, and 70 covered stents and 6 bare stents were used in TS group (Fig. 1). Ninety tracheal stents were implanted in TF group, and large Y-shaped single-plugged tracheal stent was the most common type (32.2\%). In TS group, 76 stents were implanted and the most common type was straight tracheal stent (73.7\%).

\section{Technical preparation before and after tracheal stent removal}

Chest $\mathrm{CT}$ and bronchoscopy were performed on the day before stent removal. Electrocardiograms, heart rate and blood pressure were routinely monitored during the perioperative period. Oxygen was given by nasal catheter and a sputum aspirator was prepared. Diazepam, $10 \mathrm{mg}$, and anisodamine (654-2) was injected intramuscularly to calm the patient and to reduce tracheal secretions before stent removal. Dexamethasone, $10 \mathrm{mg}$, was injected to relieve dyspnea or to improve tolerability if necessary. The sputum aspiration tube was then advanced into the tracheal for sputum drainage and to maintain tracheal patency. All patients were monitored by electrocardiogram, heart rate and blood pressure for at least $8 \mathrm{~h}$ after stent removal.

\section{Technical details of tracheal stent removal}

All interventional procedures were performed under fluoroscopy and by two to three clinically experienced experts with at least 10 years of experience in interventional treatment for airway disease. A 5F catheter and a $0.035 \mathrm{in}$. hydrophilic guide wire (Cook Corporation, Bloomington, IN, USA) were inserted into the main bronchus under topical anesthesia with lidocaine. A 10$12 \mathrm{~F}$ long sheath was inserted below the tracheal stent via a 0.035 in. stiff hydrophilic guide wire. A removal hook was introduced slowly along the sheath with its tip placed next to the distal end of stent. The whole procedure of stent removal was carried out under continuous fluoroscopy to closely monitor and to prevent complications such as stent shedding. The tracheal stent was hooked firmly and then withdrawn carefully (Fig. 2,

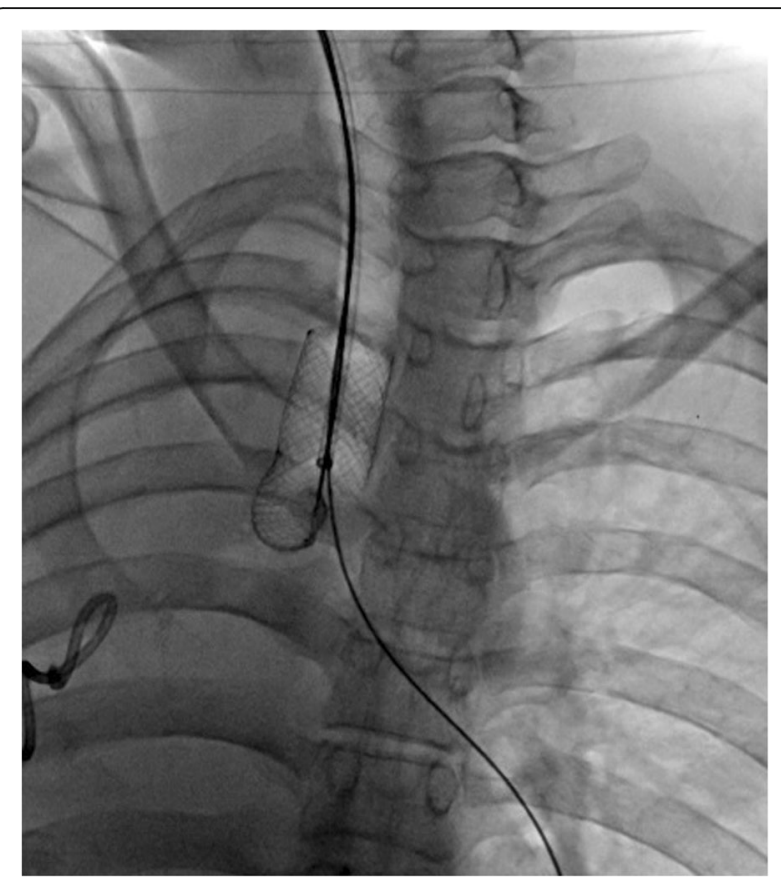

Fig. 2 Technique of tracheal stent removal. A retrieval hook was inserted through a sheath and the tip of hook was placed next to the proximal end of the stent. The stent then was carefully dissected from the tracheal wall

Video 1, Video 2). Radiography was performed again to show whether there was an overflow of contrast material after stent removal. For patients with severe stenosis within the stent due to granulation tissue, preprocedural bronchoscopy was performed and high-frequency electrosurgical excision, cryotherapy or an argon knife were used to decrease the amount of granulation tissue. Thereafter, stent removal was performed.

\section{Complications of stent removal and follow up}

All complications of stent removal were recored and analyzed. Patients were followed up after stent removal, and chest CT scans were performed. Telephone followup was used for patients who did not come to the hospital for reexamination.

\section{Statistical analysis}

Data were expressed as mean \pm standard deviation, and analyzed by student $t$ test and ANOVA. Qualitative data were expressed in percentage, and analyzed by Fisher's exact test. Patency rate was compared by Log-rank (Mantel-Cox) Test (GraphPad Software, Inc., USA). Statistical significance was considered when $p<0.05$.

\section{Results}

Patient characteristics

Ninety covered tracheal stents were inserted in the TF group and 76 tracheal stents were implanted in the TS 
group. Tracheal fistulas were caused by malignant tumor invasion or surgical removal in $81.2 \%$ patients in the TF group. There were 47 cases of lung cancer, 2 cases of thyroid cancer and 20 cases of esophageal squamous cell carcinoma. Among lung cancer, 4 cases of lung adenocarcinoma, 1 case of lung adenosquamous carcinoma, the rest are lung squamous cell carcinoma. Tracheal stenosis was caused mainly by benign primary disease requiring tracheotomy or tracheal cannula in $82.1 \%$ patients in the TS group. There were 5 cases of lung squamous cell carcinoma, 3 cases of thyroid cancer and 4 cases of esophageal squamous cell carcinoma. The success rate of stent removal was $98.9 \%(89 / 90)$ in the TF group. Only one patient underwent bronchoscopic removal for retained stent pieces after failure of fluoroscopic removal. In the TS group, the success rate of stent removal was $97.4 \%$ (74 of 76 stents) and only 2 stents retained. The mean procedure time for stent implantation or removal was similar between two groups. Tumor invasion or tumor operation was the main causes for tracheal fistula, and tracheotomy or trachea cannula was the main causes for tracheal stenosis $(p<0.0001$, Table 1).

\section{Indications for stent removal and interval}

Forty-seven stents implanted for tracheal fistula and 40 stents implanted for tracheal stenosis were routinely removed. Stent migration and stent intolerance were the main indications for early stent removal in both groups. Excessive granulation tissue increased as the time interval after implantation increased, with a mean interval of $142.1 \pm 25.9$ days for tracheal fistula and 89.9 \pm 15.0 day for tracheal stenosis, and was the most common indications for later stent removal. Interestingly, tracheal stents were routinely removed after $107.8 \pm 9.8$ days and $85.4 \pm$ 6.7 days, respectively, in the TF group and the TS group (Table 2). These two time points are consistent, suggesting that the stent should be removed about 3 months after implantation to reduce the incidence of restenosis. Six bare stents were implanted on an emergency basis in the TS group for severe tracheal stenosis. Three of these stents were removed and replaced by covered stents, with a mean duration of $8.7 \pm 3.2$ days, and one stent was replaced by a tracheal $\mathrm{T}$-tube.

\section{Complications}

The technical success rate of stent removal was 98.9 and $97.4 \%$, respectively, for $\mathrm{TF}$ and TS groups. In the TF group, 75 stents were removed in one piece. Stent fracture and retained stent pieces were found in 14 patients and 1 stent. In the TS group, 74 tracheal stents were successfully removed, including 71 in one piece and 5 with strut fracture. Two of these stents were retained and the other three retained stent pieces were successfully removed by endoscopy (Table 3 ).

Recurrence of fistula or stenosis requiring stenting was the most comment complication in both groups. Two patients showed severe dyspnea in each group and underwent endotracheal intubation and mechanical ventilation. Symptoms were relieved and the endotracheal tube was removed within $4 \mathrm{~h}$. Massive hemoptysis occurred in two patients during stent removal in the TF group. One patient died of asphyxia caused by massive hemorrhage and bleeding ceased in the other patient after administration of pituitrin. Two patients died perioperatively in the TS group, resulting in a clinical success rate of $94.7 \%(72 / 76)$. One patient with tracheal stenosis after resection of esophageal carcinoma died of

Table 1 Patient characteristics

\begin{tabular}{|c|c|c|c|}
\hline Characteristics & TF group & TS group & $p$ \\
\hline Patients, N & 85 & 67 & \\
\hline Mean age (range), years. & $54.9 \pm 1.3(15-81)$ & $51.1 \pm 2.2(12-85)$ & 0.1306 \\
\hline Male/female gender, $\mathrm{N}$ & $72 / 13$ & $39 / 28$ & 0.0004 \\
\hline Malignancy/benign primary disease, N & $69 / 16$ & $12 / 55$ & $<0.0001$ \\
\hline Procedure time of implantation & $29.1 \pm 1.6(10-53)$ & $26.8 \pm 1.9(9-60)$ & 0.3598 \\
\hline Procedure time of stent removal & $19.0 \pm 1.3$ & $23.3 \pm 2.0$ & 0.0715 \\
\hline \multicolumn{4}{|l|}{ Causes of disease, N (\%) } \\
\hline Tracheotomy/Trachea cannula & $0(0 \%)$ & $32(47.8 \%)$ & $<0.0001$ \\
\hline Tumor invasion/Tumor operation & 69 (81.2\%) & $12(17.9 \%)$ & $<0.0001$ \\
\hline External pressure & $0(0 \%)$ & $7(10.4 \%)$ & 0.0027 \\
\hline Surgery for inflammatory disease & $9(10.6 \%)$ & $6(9.0 \%)$ & 0.7908 \\
\hline Tracheal stent implantation & $0(0 \%)$ & $5(7.5 \%)$ & 0.0153 \\
\hline Tracheal mechanical injury or trauma & $3(3.5 \%)$ & $3(4.5 \%)$ & 1.0000 \\
\hline Others & $4(4.7 \%)$ & 2 (3.0\%) & 0.6947 \\
\hline
\end{tabular}


Table 2 Indications of stent removal and interval

\begin{tabular}{|c|c|c|c|}
\hline & TF group & TS group & $p$ \\
\hline \multicolumn{4}{|l|}{ Indications of removal, N (\%) } \\
\hline Routine removal & $47(52.2 \%)$ & $40(52.6 \%)$ & 1.0000 \\
\hline Excessive granulation tissue & $11(12.2 \%)$ & $15(19.7 \%)$ & 0.2041 \\
\hline Stent migration & $12(13.3 \%)$ & $5(6.6 \%)$ & 0.2011 \\
\hline Intolerance of stenting & $8(8.9 \%)$ & $6(7.9 \%)$ & 1.0000 \\
\hline Inadequate expansion and deformation & $0(0.0 \%)$ & $5(6.6 \%)$ & 0.0187 \\
\hline Strut fracture & $4(4.4 \%)$ & $1(1.3 \%)$ & 0.3764 \\
\hline Recurrence of fistula & $8(8.9 \%)$ & - & - \\
\hline Replacement of bare stent & - & $4(5.3 \%)$ & - \\
\hline \multicolumn{4}{|l|}{ Interval between placement and removal, days } \\
\hline Routine removal & $107.8 \pm 9.8$ & $85.4 \pm 6.7$ & 0.0703 \\
\hline Excessive granulation tissue & $142.1 \pm 25.9$ & $89.9 \pm 15.0$ & 0.0744 \\
\hline Stent migration & $20.2 \pm 8.1$ & $27.0 \pm 19.2$ & 0.7003 \\
\hline Intolerance of stenting & $18.9 \pm 10.5$ & $8.3 \pm 4.3$ & 0.4256 \\
\hline Inadequate expansion and deformation & - & $2.0 \pm 2.0$ & - \\
\hline Strut fracture & $97.0 \pm 14.8$ & 105 & - \\
\hline Recurrence of fistula & $60.6 \pm 36.7$ & - & - \\
\hline Replacement of bare stent & - & $8.7 \pm 3.2$ & - \\
\hline Total (range) & $89.5 \pm 8.3(0-435)$ & $68.1 \pm 6.1(0-221)$ & 0.0439 \\
\hline
\end{tabular}

massive hemoptysis 3 days after stent removal. The other patient died of respiratory failure 2 days after insertion of a second stent.

\section{Stent replacement after removal}

Eight stents were replaced immediately and five stents were replaced 5 to 9 days after removal in the TF group. Replacements included Y-type tracheal stents $(n=5)$, Ltype tracheal stents $(n=3), Y$-shaped single-plugged stents $(n=2)$, straight tracheal stents $(n=2)$ and 1 combination of a large and a small Y-type tracheal stent. One patient required stenting due to proximal re-

Table 3 Complications of stent removal

\begin{tabular}{llll}
\hline Complication & TF group & TS group & $\boldsymbol{p}$ \\
\hline Recurrence requires stenting & $13(14.4 \%)$ & $9(11.8 \%)$ & 0.6538 \\
Y-type tracheal stent & $6(6.7 \%)$ & $2(2.6 \%)$ & 0.2914 \\
Straight tracheal stent & $3(3.3 \%)$ & $7(9.2 \%)$ & 0.1886 \\
L-type tracheal stent & $3(3.3 \%)$ & $0(0.0 \%)$ & 0.2508 \\
$\quad$ plugged bullet-shaped stent & $1(1.1 \%)$ & $0(0.0 \%)$ & 1.0000 \\
Strut fracture and residue & $1(1.1 \%)$ & $5(6.6 \%)$ & 0.0944 \\
Mucosal tear with massive bleeding & $2(2.2 \%)$ & $1(1.3 \%)$ & 1.0000 \\
Reobstruction requiring stenting & $1(1.1 \%)$ & $0(0.0 \%)$ & 1.0000 \\
Dyspne need for mechanical ventilation & $2(2.2 \%)$ & $2(2.6 \%)$ & 1.0000 \\
Total complications & $19(21.1 \%)$ & $17(22.4 \%)$ & 0.8525 \\
\hline
\end{tabular}

$N$ number obstruction of the stent after removal of a straight tracheal stent, and the same size straight tracheal stent was implanted immediately. In TS group, 20 tracheal stents (15 straight tracheal stents and $5 \mathrm{Y}$ type tracheal stents) were implanted again after removal for replacement of bare stents $(n=3)$, or due to restenosis $(n=9)$, migration $(n=3)$, inadequate expansion $(n=3)$, and intolerance $(n=2)$.

\section{Follow up}

All surviving patients were followed up. Five patients (6.0\%) were lost during follow up in the TF group and four were lost (6.2\%) in the TS group. Thirty-three patients were cured and 20 patients were improved in the TF group. Twenty-four patients died in the TF group, and tumor progression was the most common cause of death. One of the 24 patients died of respiratory failure due to asphyxia, and two patients died of massive hemoptysis and hematemesis. In the TS group, 29 patients were cured, 20 patients were improved and 6 patients underwent tracheotomy and tracheal $\mathrm{T}$-tube implantation after stent removal (Table 4). The 0.5-, 3-, 6-year survival rates were $90.3,59.6$, and $36.1 \%$ for TF group, and 80.4, 75.7, 75.7\% for TS group (Fig. 3).

\section{Discussion}

Tracheal resection with primary anastomosis is the standard of care for the treatment of tracheal stenosis. 
Table 4 Clinical efficacy and death evaluation during follow-up

\begin{tabular}{llll}
\hline & TF group & TS group & $\boldsymbol{p}$ \\
\hline Loss of follow up & $5 / 84(6.0 \%)$ & $4 / 65(6.2 \%)$ & 1.0000 \\
Clinical efficacy evaluation, & N (\%) & & \\
$\quad$ Cured & $33(39.3 \%)$ & $29(44.6 \%)$ & 0.6154 \\
Improved & $20(23.8 \%)$ & $20(30.8 \%)$ & 0.3576 \\
Invalid & $2(2.4 \%)$ & $3(4.6 \%)$ & 0.6534 \\
Death & $24(28.6 \%)$ & $9(13.8 \%)$ & 0.0458 \\
Causes of death, N (\%) & & & \\
$\quad$ Tumor progression & $21(25.0 \%)$ & $5(7.7 \%)$ & 0.0081 \\
$\quad$ Asphyxia & $1(1.2 \%)$ & $4(6.2 \%)$ & 0.1679 \\
$\quad$ Massive bleeding & $2(2.4 \%)$ & $0(0.0 \%)$ & 0.5048 \\
\hline$N$ number & & &
\end{tabular}

However, tracheal resection is not suitable for long segmental stenosis, which also is associated with the complication of tracheal restenosis after resection. In this study, most of the patients enrolled had conditions which were complicated by underlying diseases and were not candidates for resection under general anesthesia. Tracheal stents are widely used clinically for the treatment of tracheal fistula [4-7] or tracheal stenosis [813]. However, tracheal stent placement may lead to a series of complications, and stent removal is sometimes necessary [23]. Currently, a tracheal stent is commonly removed under bronchoscopic guidance and general anesthesia [17, 24-27] or local anesthesia [28, 29]. Few studies have reported fluoroscopic removal of tracheal stents [12, 21, 22], and no study has compared the longterm outcomes and complications associated with fluoroscopy-guided removal of tracheal stents inserted for tracheal fistula or tracheal stenosis.

In the present study, $97.4 \%$ of stents implanted for tracheal stenosis were successfully removed under fluoroscopic guidance, which is higher than that reported by Verma et al. for silicon stent removal in patients with

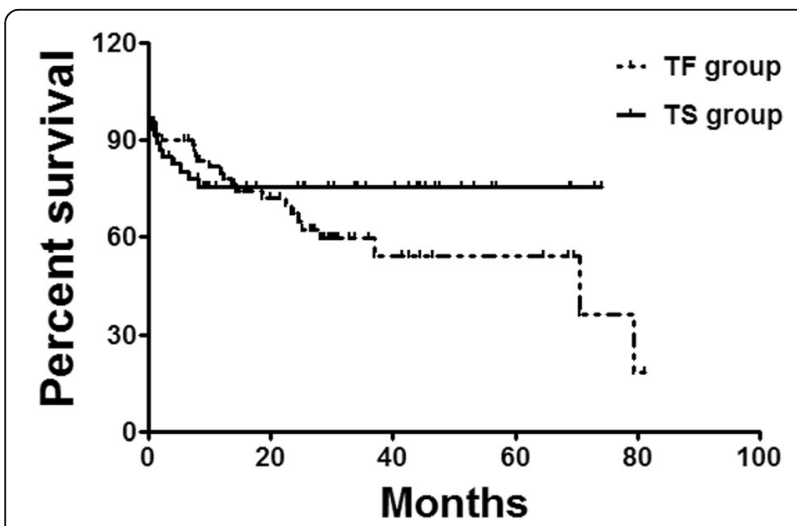

Fig. 3 Survival rate follow up. The 0.5-, 3-, 6-year survival rates were 90.3, 59.6, and $36.1 \%$ for TF group, and $80.4,75.7,75.7 \%$ for TS group tracheobronchial stenosis [30]. Additionally, in their study $83.3 \%$ of stents were removed in one piece and only one stent showed retained stent pieces. In a study by Lunn et al., $73 \%$ of stents were removed piecemeal with rigid alligator forceps [24]. Our data indicate that fluoroscopy-guided removal of tracheal stents is a feasible procedure for tracheal fistula and tracheal stenosis.

Although the process of fluoroscopy-guided removal of tracheal stents is rapid, serious complications may occur during stent removal, such as massive bleeding, acute tracheal obstruction, and even death [24, 31, 32]. In our study, one patient patient in the TF the group died of asphyxia caused by massive hemorrhage. In the TS group, one patient died of massive hemoptysis 3 days after stent removal, and another patient died of respiratory failure. The overall perioperative mortality of stent removal under fluoroscopy was $1.97 \%$, indicating that the technique was safe. In addition, the total incidence of complications was 21.1 and $22.4 \%$, respectively, for the TF and TS groups. Compared with previous reports of stent removal by rigid bronchoscopy [24, 25, 29, 31], we showed a lower rate of complications.

Stent placement and removal with rigid bronchoscope under general anesthesia remains gold standard. Bronchoscopic technique has the advantage of direct visualization of tumor recurrence which can avoid some complications including hemoptysis in patients with malignancy. Theoretically, these two patients may be saved if bronchospcopic hemostasis was uesd. It should be noted that clinicians should pay attention to the risk of hemoptysis for patients with malignant tumors and, if necessary, a combination with endoscopic hemostasis should be used to further improve its safety. By contrast, fluoroscopic placement and removal of metallic stents may be more suitable for elder patients and patients who combined with severe co-morbidities or refuse general anesthesia.

Questions remain about the length of time that an indwelling stent should remain in place before removal in the treatment of tracheal disease [25]. The incidence of stent restenosis induced by granulation tissue hyperplasia and stent fracture may increase as indwelling time increases [33-35], and may lead to difficulty or failure of stent removal [28]. According to our findings, excessive granulation tissue was found $142.1 \pm 25.9$ days after stenting for tracheal fistula, and $89.9 \pm 15.0$ day after stenting for tracheal stenosis. Interestingly, tracheal stents were routinely removed about 3 months after implantation in our study. An indwelling interval of one to 3 months should be recommended for stent removal to avoid long-term complications.

There are weaknesses in our study. It was a retrospective study conducted in a single center. We solely performed stent removal under fluoroscopic guidance. In 
future studies, stents should be removed by a variety of technologies including bronchoscopy.

\section{Conclusions}

Fluoroscopic removal of tracheal stent is safe and effective for both tracheal fistula and tracheal stenosis, with no significant difference. Recurrence of fistula or stenosis requiring stenting was the most comment complication. Clinicians should pay attention to the risk of hemoptysis for patients with malignant tumors and a combination with endoscopic hemostasis may help improve its safety.

\section{Supplementary Information}

The online version contains supplementary material available at https://doi. org/10.1186/s12890-020-01349-7.

Additional file 1: Video 1. Stent removal for straight tracheal stent. Additional file 2: Video 2. Stent removal for Y-type tracheal stent.

\section{Abbreviations}

CT: Computed tomography; TF: Tracheal fistula; TS: Tracheal stenosis

\section{Acknowledgements}

Not applicable

\section{Authors' contributions}

YHB, JDL, XWH and RJZ designed study. YHB, JDL, LLB performed study. YHB, JDL, LLB collected and analyzed data. All authors wrote the paper and finally approved of the version to be published.

\section{Funding}

This work was supported by National Natural Science Foundation of China (Grant No. 81501569). No funding body participated in the design of the study and collection, analysis, and interpretation of data and in writing the manuscript.

\section{Availability of data and materials}

The datasets used and/or analyzed during the current study are available from the corresponding author on reasonable request.

\section{Ethics approval and consent to participate}

This study obtained approval from the institutional review board of Zhengzhou University First Affiliated Hospital to review and publish information obtained from patient records. Written informed consent was obtained from all patients.

\section{Consent for publication}

We informed each patient of the publication, which includes the individuals personal data in any form (including individual details, images, or videos), and obtained written informed consent.

\section{Competing interests}

The authors declare that they have no competing interests.

\section{Author details}

${ }^{1}$ Department of Interventional Radiology, The First Affiliated Hospital of Zhengzhou University, No.1, East Jian She Road, Zhengzhou 450052, China. ${ }^{2}$ Department of Thoracic Surgery, The First Affiliated Hospital of Zhengzhou University, Zhengzhou, China.
Received: 11 February 2020 Accepted: 12 November 2020

Published online: 07 January 2021

\section{References}

1. Turk AE, Karanas YL, Cannon W, Chang J. Staged closure of complicated bronchopleural fistulas. Ann Plast Surg. 2000;45:560-4.

2. Fernando HC, Sherwood JT, Krimsky W. Endoscopic therapies and stents for benign airway disorders: where are we, and where are we heading? Ann Thorac Surg. 2010;89:S2183-7.

3. Simonds AK, Irving JD, Clarke SW, Dick R. Use of expandable metal stents in the treatment of bronchial obstruction. Thorax. 1989:44:680-1.

4. Han X, Li L, Zhao Y, Liu C, Jiao D, Ren K, Wu G. Individualized airwaycovered stent implantation therapy for thoracogastric airway fistula after esophagectomy. Surg Endosc. 2017;31:1713-8.

5. Han X, Wu G, Li Y, Li M. A novel approach: treatment of bronchial stump fistula with a plugged, bullet-shaped, angled stent. Ann Thorac Surg. 2006; 81:1867-71.

6. Wu G, Li ZM, Han XW, Wang ZG, Lu HB, Zhu M, Ren KW. Right bronchopleural fistula treated with a novel, Y-shaped, single-plugged, covered, metallic airway stent. Acta Radiol. 2013;54:656-60.

7. Cui YF, Fu YF, Li DC, Xu H. Percutaneous recanalization for hepatic vein-type Budd-Chiari syndrome: long-term patency and survival. Hepatol Int. 2016;10: 363-9.

8. Stockton PA, Ledson MJ, Hind CR, Walshaw MJ. Bronchoscopic insertion of Gianturco stents for the palliation of malignant lung disease: 10 year experience. Lung Cancer. 2003;42:113-7.

9. Prasad M, Bent JP, Ward RF, April MM. Endoscopically placed nitinol stents for pediatric tracheal obstruction. Int J Pediatr Otorhinolaryngol. 2002;66: 155-60.

10. Han X, Al-Tariq Q, Zhao Y, Li L, Cheng Z, Wang H, Liu C, Jiao D, Wu G. Customized hinged covered metallic stents for the treatment of benign main bronchial stenosis. Ann Thorac Surg. 2017;104:420-5.

11. Thornton RH, Gordon RL, Kerlan RK, LaBerge JM, Wilson MW, Wolanske KA Gotway MB, Hastings GS, Golden JA. Outcomes of tracheobronchial stent placement for benign disease. Radiology. 2006;240:273-82.

12. Park JH, Kim PH, Shin JH, Tsauo J, Kim MT, Cho YC, Kim JH, Song HY. Removal of retrievable self-expandable metallic tracheobronchial stents: an 18-year experience in a single center. Cardiovasc Intervent Radiol. 2016;39: 1611-9.

13. Ma J, Han X, Wu G, Jiao D, Ren K, Bi Y. Outcomes of temporary partially covered stent placement for benign tracheobronchial stenosis. Cardiovasc Intervent Radiol. 2016:39:1144-51.

14. Freitag L, Ernst A, Unger M, Kovitz K, Marquette $\mathrm{CH}$. A proposed classification system of central airway stenosis. Eur Respir J. 2007;30:7-12.

15. Gaissert HA, Grillo HC, Wright CD, Donahue DM, Wain JC, Mathisen DJ. Complication of benign tracheobronchial strictures by self-expanding metal stents. J Thorac Cardiovasc Surg. 2003;126:744-7.

16. Miyazawa T, Yamakido M, Ikeda S, Furukawa K, Takiguchi Y, Tada H, Shirakusa T. Implantation of ultraflex nitinol stents in malignant tracheobronchial stenoses. Chest. 2000;118:959-65.

17. Filler RM, Forte V, Chait P. Tracheobronchial stenting for the treatment of airway obstruction. J Pediatr Surg. 1998;33:304-11.

18. Rousseau H, Dahan M, Lauque D, Carre P, Didier A, Bilbao I, Herrero J, Blancjouvant F, Joffre F. Self-expandable prostheses in the tracheobronchial tree. Radiology. 1993;188:199-203.

19. Nashef SA, Dromer C, Velly JF, Labrousse L, Couraud L. Expanding wire stents in benign tracheobronchial disease: indications and complications. Ann Thorac Surg. 1992;54:937-40.

20. Zakaluzny SA, Lane JD, Mair EA. Complications of tracheobronchial airway stents. Otolaryngol Head Neck Surg. 2003;128:478-88.

21. Kapoor BS, Rathmann G, Shrawny S, Dunitz J, Hunter D. Retrieving a malpositioned tracheobronchial stent utilizing Amplatz gooseneck snare: a case report. Cardiovasc Intervent Radiol. 2004:27:291-3.

22. Song HY, Shim TS, Kang SG, Jung GS, Lee DY, Kim TH, Park S, Ahn YM, Kim WS. Tracheobronchial strictures: treatment with a polyurethane-covered retrievable expandable nitinol stent--initial experience. Radiology. 1999;213: 905-12

23. Han XW, Wu G, Li YD, Zhang QX, Guan S, Ma N, Ma J. Overcoming the delivery limitation: results of an approach to implanting an integrated selfexpanding Y-shaped metallic stent in the carina. J Vasc Interv Radiol. 2008; 19:742-7. 
24. Lunn W, Feller-Kopman D, Wahidi M, Ashiku S, Thurer R, Ernst A. Endoscopic removal of metallic airway stents. Chest. 2005;127:2106-12.

25. Noppen M, Stratakos G, D'Haese J, Meysman M, Vinken W. Removal of covered self-expandable metallic airway stents in benign disorders: indications, technique, and outcomes. Chest. 2005;127:482-7.

26. Dooms C, De Keukeleire T, Janssens A, Carron K. Performance of fully covered self-expanding metallic stents in benign airway strictures. Respiration. 2009;77:420-6.

27. Chan AL, Juarez MM, Allen RP, Albertson TE. Do airway metallic stents for benign lesions confer too costly a benefit? BMC Pulm Med. 2008;8:7.

28. Chung FT, Chen GY, Chou CL, Chen HC, Yu CT, Kuo CH, Lin SM, Kuo HP. Remove airway ultraflex stents by flexible bronchoscope. Am J Med Sci. 2012;343:267-72.

29. Fruchter O, Raviv Y, Fox BD, Kramer MR. Removal of metallic tracheobronchial stents in lung transplantation with flexible bronchoscopy. J Cardiothorac Surg. 2010;5:72.

30. Verma A, Park HY, Lim SY, Um SW, Koh WJ, Suh GY, Chung MP, Kwon OJ, Kim H. Posttuberculosis tracheobronchial stenosis: use of CT to optimize the time of silicone stent removal. Radiology. 2012;263:562-8.

31. Gottlieb J, Fuehner T, Dierich M, Wiesner O, Simon AR, Welte T. Are metallic stents really safe? A long-term analysis in lung transplant recipients. Eur Respir J. 2009;34:1417-22.

32. Murthy SC, Gildea TR, Mehta AC. Removal of self-expandable metallic stents: is it possible? Semin Respir Crit Care Med. 2004;25:381-5.

33. Chung FT, Lin SM, Chen HC, Chou CL, Yu CT, Liu CY, Wang CH, Lin HC, Huang CD, Kuo HP. Factors leading to tracheobronchial self-expandable metallic stent fracture. J Thorac Cardiovasc Surg. 2008;136:1328-35.

34. Chung FT, Lin SM, Chou CL, Chen HC, Liu CY, Yu CT, Kuo HP. Factors leading to obstructive granulation tissue formation after ultraflex stenting in benign tracheal narrowing. Thorac Cardiovasc Surg. 2010;58:102-7.

35. Chung FT, Chen HC, Chou CL, Yu CT, Kuo CH, Kuo HP, Lin SM. An outcome analysis of self-expandable metallic stents in central airway obstruction: a cohort study. J Cardiothorac Surg. 2011;6:46.

\section{Publisher's Note}

Springer Nature remains neutral with regard to jurisdictional claims in published maps and institutional affiliations.

Ready to submit your research? Choose BMC and benefit from:

- fast, convenient online submission

- thorough peer review by experienced researchers in your field

- rapid publication on acceptance

- support for research data, including large and complex data types

- gold Open Access which fosters wider collaboration and increased citations

- maximum visibility for your research: over $100 \mathrm{M}$ website views per year

At $\mathrm{BMC}$, research is always in progress.

Learn more biomedcentral.com/submissions 